\title{
Um olhar sobre o papel da mulher rendeira na história da moda brasileira
} A look at the role of the lacemaker woman in the Brazilian fashion history

\author{
Vera Lucia Felippi da Silva \\ Mestre em Design pela Universidade Federal do Rio Grande do Sul \\ verafelippi@hotmail.com
}

Evelise Anicet Rüthschilling

Docente na UFRGS anicet@ufrgs.br

Joana Bosak de Figueiredo

Docente no Bacharelado em História da Arte - UFRGS joanabosak@gmail.com

\section{Resumo}

O presente artigo faz uma reflexão sobre o papel da mulher rendeira na sociedade brasileira, discutindo as transformações, a apropriação do conhecimento e as ressignificações do fazer manual de rendas no século XX e XXI. Para isso, apoia-se na análise de imbricamentos sociais e culturais com abordagem pela micro-história de vida da senhora da alta sociedade carioca, rendeira, usuária e colecionadora. Analisando os dois principais cenários sociais, a elite e a classe trabalhadora, verificou-se que a relação de produção de rendas, nos séculos estudados, modificaram-se em decorrência do atual modelo de vida das mulheres.

Palavras-chave: História da moda; mulher rendeira; sociedade brasileira

\section{Abstract}

This article aims to study the role of the lacemaker woman in the Brazilian society, discussing the changes, the gain of knowledge and the reinterpretation of lace made by hand in the twentieth and twenty-first century. For this, it's based on the 


\section{ModaPalavra E-periódico}

analysis of social and cultural aspects as well as the approach the micro-history life of the elite lady of Rio de Janeiro, lace maker, consumer and collector. Analyzing the two main social settings, the elite and the working class, it was found that lace production relation, in all the centuries studied, have changed due to the current model of women's live.

Key words: fashion history; lace maker woman; Brazilian society

\section{Introdução}

No Brasil o processo artesanal de tecelagem de rendas se mantém nos últimos séculos como atividade predominantemente feminina nas diferentes camadas sociais. Essa tradição do uso e fazer das rendas remonta ao período da Colônia e do Império, em que a renda era parte fundamental da indumentária feminina:

Traziam, debaixo da saia principal, duas saias de algodão, enfeitadas com barrado de renda (a chamada 'renda de ponta') e bem engomadas, além da 'camisa de dentro' (espécie de combinação também debruada de rendarenascença) (FALCI, 2010, p. 245).

Do século XX para o XXI, o uso e o fazer de rendas mantiveram sua importância, mas em decorrência das conquistas feministas o cenário se modificou e, para compreender essa transição, o estudo faz uma reflexão sobre o papel da mulher rendeira do século XX na sociedade brasileira, aplicando abordagem da Micro-História. Essa abordagem é uma metodologia de pesquisa em História, definida como uma prática de estudo em que é usado "um aspecto reduzido para enxergar mais longe" (BARROS, 2007, p.170), ampliando a percepção dos elementos em questão, pelo modo como se vê o microuniverso estudado. Segundo Barros (2007, p. 171), a ideia é que “embora não seja possível enxergar a sociedade inteira a partir de um fragmento social, por mais que ele seja cuidadosamente bem escolhido, será possível enxergar algo da realidade social que envolve o fragmento humano examinado".

A metodologia proposta foi considerada adequada devido ao rastro dos indícios encontrados que se propõe abordar, a partir de uma trajetória específica e de uma coleção como índices culturais que permitem identificar ressonâncias em uma história coletiva, referente a uma época e a uma cultura. Esses indícios encontrados ou 


\section{ModaPalavra E-periódico}

reconstruídos, são fundamentais ao paradigma postulado por Ginzburg (1994), dentro da perspectiva da Micro-História, e propõem o olhar em uma escala reduzida.

Carlo Ginzburg trata das fontes na Micro-História com o uso do que chama "paradigma indiciário", caracterizado pela capacidade de dados que aparentemente foram ignorados, de "remontar uma realidade complexa, não experimentável diretamente" (1994, p. 152). Trata-se de uma abordagem em parte dedutiva, em que, como um "detetive", o historiador se ampara nas evidências existentes para montar uma trilha de rastros, que ao ser posta em relevo e em comparação, pode estabelecer uma rede de nexos e relações possíveis de criar e mesmo "desvendar" um acontecimento ou situações em tempos passados.

Importante salientar que a Micro-História possui características diferentes das de estudo de caso. De acordo com Barros (2007, p.175), no caso da Micro-História o recorte escolhido para estudo "existe em função de um problema, é este recorte que define o problema", estando ambos intimamente ligados. No estudo de caso se tem um problema anterior para o qual é estabelecido um recorte no interesse de viabilizar a pesquisa e/ou se tem um recorte prévio dentro do qual vão surgindo os problemas.

Pela abordagem usada, não se trata de traçar a biografia de um indivíduo por si; sua vida está sendo analisada em função de fragmentos deixados que nos trazem e fornecem subsídios para discutir um problema mais amplo, apresentado pelo olhar que se pretende lançar sobre o papel da mulher rendeira na sociedade brasileira, apoiado em dados levantados no Rio de Janeiro, Santa Catarina e Ceará.

A busca de evidências reconstruídas a partir de discursos fragmentários, estabelece a trajetória da mulher que pertenceu a uma tradicional família carioca, rendeira, usuária e colecionadora de rendas que constituiu um acervo, hoje estudado cientificamente em nível de doutorado. $\mathrm{O}$ acervo nos permite discutir a questão social e a importância de sua materialidade, sendo esse testemunho e documento de um período, considerando-o objeto de estudo da cultura material.

Nesta análise, a renda, como trama, imagem e cultura material não é só representação: é o indício fundamental; o primeiro rastro do fio de Ariadne ${ }^{1}$ que nos conduzirá ao desenrolar do labirinto a ser desvendado. Daí chegamos à colecionadora, à família dela, à sua pertença sócio-econômica e cultural, à cidade, à época, ao papel feminino, à história da mulher rendeira no Brasil.

\footnotetext{
1 Personagem da mitologia grega, que se é salva do labirinto do Minotauro por um fio, que a leva até a saída.
} 


\section{ModaPalavra E-periódico}

A micro-história aceita que se tomem como verdadeiras as possibilidades daquilo que reverbera no seu universo próximo, verificáveis através de outros trabalhos analisados e do que já se conhece da história da mulher em situação semelhante à época.

O estudo ancorado na abordagem proposta, bem como a seleção bibliográfica de apoio, nos permite refletir sobre o papel da mulher rendeira no Brasil, buscando compreender os processos de transformação, apropriação do conhecimento e as ressignificações do fazer manual da renda dentro de uma perspectiva maior, que intenta situar o papel da mulher e de seus "fazeres" no século XX e XXI.

\section{A mulher rendeira no século $\mathrm{XX}$}

$\mathrm{O}$ artigo "Continuidades e rupturas no papel da mulher brasileira no século XX" (BIASOLI-ALVES, 2000) enfatiza que, para a mulher ser socialmente aceita, eram levados em consideração os padrões de comportamento e atributos. De acordo com a autora os valores ligados ao universo feminino, no período compreendido de 1890 a 1930/40 eram: submissão, delicadeza no trato, pureza, capacidade de doação, prendas domésticas e habilidades manuais.

A partir dos anos 1930 inicia-se um período de transição (social, cultural e econômica) em que a mulher tem espaço na escolarização e na profissionalização, mas as maiores expectativas ainda recaem sobre o sexo masculino (BIASOLI-ALVES, 2000). Mesmo nesse contexto a mulher ainda carrega muitos dos valores do início do século $\mathrm{XX}$, tanto as que pertencem às camadas da elite, quanto àquelas das camadas menos favorecidas economicamente da sociedade (RAGO, 2010).

De acordo com Gilda de Mello e Souza (1987), no capítulo em que trata do antagonismo entre o sexo feminino e masculino, a autora considera que, após as duas grandes guerras mundiais, as oposições entre os sexos foram atenuadas pois "atiraram as mulheres, de improviso, às tarefas dos homens" (1987, p. 56). Ainda de acordo com a autora, as mudanças afetaram a estrutura social, a divisão do trabalho, os costumes, a moral e a vestimenta. Além disso, salienta-se que as mulheres foram libertadas de uma "série de atividades produtivas que até então se realizavam no âmbito doméstico" (GILDA, 1987, p.89), principalmente nos grandes centros urbanos, pois ali encontravase com mais facilidade artigos industrializados (tecidos, rendas, roupas, chapéus, etc.).

Mesmo diante das mudanças que ocorreram durante o século XX, ainda persistem interesses e particularidades nas "prendas e habilidades domésticas", dentre 


\title{
ModaPalavra E-periódico
}

elas o fazer manual de rendas. Nas camadas economicamente menos favorecidas, a produção feita pelas mulheres assume uma importância de complementação financeira do rendimento familiar. Segundo Arthur Ramos ${ }^{2}$ (1948, apud OLIVEIRA, 2014, p. 66) a produção de renda era feita "em sua maior parte, por mulheres negras e mestiças. Filhas e mulheres de pescadores e, em alguns casos, lavradores, quase sempre analfabetas e auxiliam na subsistência de família numerosa."

Esse fato pode ser verificado no contexto de Florianópolis, polo de produção de renda de bilros, até os dias de hoje, onde Bergamim (2013) comenta:

\begin{abstract}
As rendas aparecem quase que exclusivamente como complemento na renda mensal da família, como uma atividade extra que a mulher realizava, além dos afazeres domésticos e de atividades secundárias junto à pesca e a agricultura, que realizavam em auxílio aos homens da casa. Digo auxílio, pois as atividades femininas se restringiram, por muito tempo, ao âmbito doméstico, fazendo com que as mulheres acumulassem assim, diversas tarefas ao longo do dia (BERGAMIN, 2013, p.15).
\end{abstract}

Por outro lado, o tecimento de rendas feito por mulheres da elite, assume um papel diverso. Como não havia o intuito de comercialização e nem a necessidade de complementação de renda familiar, podia ser considerada como uma atividade de lazer. As mulheres produziam rendas que eram usadas para adornar suas roupas, roupas de familiares (principalmente filhas), peças de enxoval e decoração para a casa.

\section{A Micro-História da Sra. Lucy Niemeyer}

Neste estudo a abordagem da Micro-História contribui para reduzir a escala de observação com a intenção de melhor compreender aspectos relativos a mulher rendeira do século passado e compará-los aos do século XXI. Segundo Barros (2007, p.175) "são comuns as escolhas de vidas ou trajetórias individuais para a realização de uma observação intensiva, e algumas vezes anônimo".

O indivíduo aqui estudado não é anônimo, trata-se da Sra. Lucy Niemeyer, e leva-se em conta sua posição social face ao entorno: ela pertencia a uma família abastada, da Zona Sul do Rio de Janeiro da primeira metade do século XX. Sendo assim, com o indivíduo situado em seu tempo e espaço, podemos compreender aspectos específicos que se propagam em aspectos mais amplos da sociedade.

\footnotetext{
2 Citação do livro de Arthur e Luiza Ramos “A renda de bilros e sua aculturação no Brasil”, livro importantíssimo para o estudo das rendas no Brasil, porém escasso para pesquisa em bibliotecas e aquisição.
} 


\section{ModaPalavra E-periódico}

A Sra. Lucy $^{3}$ nasceu em 19 de julho de 1906 e faleceu em 23 de dezembro de 1992. De acordo com sua filha, a mãe aprendeu a confeccionar as rendas ainda na adolescência, como era de costume na época. Tinha muita habilidade manual e refinado senso estético. Provavelmente tenha aprendido com as irmãs e/ou amigas, pois era filha caçula de dez irmãos, sendo cinco mulheres.

Lucy, a filha, não se recorda de sua mãe ter repassado ou ensinado as técnicas que dominava para outras pessoas, nem mesmo saberia citar quais eram essas técnicas de domínio. Mas, quando sua mãe faleceu, deixou grande conjunto de rendas de extrema beleza, que carregam grande conhecimento técnico. $\mathrm{Na}$ análise da MicroHistória da Sra. Lucy, essa pesquisa buscou seguir os atributos do papel da mulher rendeira carioca visando salvaguardar toda a riqueza material e simbólica.

Seria válido afirmar que os aspectos de vida da Sra. Lucy sejam válidos para todas as mulheres na mesma condição social? Não é possível afirmar, pois a MicroHistória não trabalha com generalizações (BARROS, 2007). O indivíduo humano analisado, ou seja, a figura da Sra. Lucy e sua coleção de rendas fornece o "algo" para o estudo, a realidade social e cultural de uma época.

\section{$O$ acervo de rendas}

A coleção de rendas deixada pela Sra. Lucy é composta por itens confeccionados em processos industriais e artesanais de diversas técnicas. Dentre as amostras artesanais encontradas não é possível identificar quais foram feitas por ela e não há indícios ou registros que comprovem a origem de cada item. Provavelmente essa coleção foi se constituindo pela necessidade de ter "amostras" para reproduzir pontos e criar novos desenhos. No caso das rendas feitas em processos industriais, podem terem sido compradas para adornar roupas ou para a decoração da casa.

O esforço e cuidado da Sra. Lucy em colecionar as rendas nos fornece "documentos", registros que ilustram parte dos afazeres de mulheres de uma época, entendidos como o legado cultural de um período e da atividade de tecer as rendas. Esses documentos permitem a reflexão sobre o modo de vida e resulta testemunho de um período e do fazer de uma sociedade, contribuindo de forma significativa aos estudos da cultura. Trata-se de fontes documentais, portadoras de múltiplos sentidos,

\footnotetext{
3 As informações descritas sobre a Sra. Lucy Niemeyer foram obtidas a partir de troca de mensagens com sua filha, também chamada Lucy Niemeyer.
} 


\section{ModaPalavra E-periódico}

narrativas, significados e enredos. Além disso, coopera para análises práticas e aplicáveis de processos de design têxtil e técnicas de tecelagem de rendas.

A coleção de rendas foi doada por sua filha, em 2011, para o Núcleo de Design de Superfície da Universidade Federal do Rio Grande do Sul onde, desde então, tem sido objeto de estudos científicos em nível de mestrado e doutorado, visando não só o estudo do acervo em si, como promovendo sua interação com práticas contemporâneas de desenvolvimento de produto. Em nível de doutorado está sendo construído um site na Internet para disponibilizar consulta online ao acervo, bem como informações históricas e técnicas, resultadas da pesquisa.

O acervo é constituído de 186 itens de renda que compreendem detalhes decorativos para aplicação em roupas (bolsos, golas, barrados), rendas lineares de diversas medidas e bases para construção de renda filé.

O conjunto de rendas se configura como acervo a partir do momento que saiu do meio familiar da Sra. Lucy e passou para as mãos de uma instituição para o estudo científico. Nesse estágio, assumem um novo papel (OLIVEIRA, 2014): o de objetos de estudo da cultural material. Esses objetos foram criados no passado, continuam a existir no presente e podem se perpetuar. Segundo Prown (1994), eles nos oferecem uma oportunidade pela qual nos deparamos com o passado, temos experiência sensorial direta tornando-se importantes na medida em que pode ser experimentado e interpretado como evidência significativa das influências culturais que refletem e incorporam.

No campo da história da cultura material, não é o objeto em si mesmo que é examinado, mas seus usos, suas apropriações sociais, as técnicas envolvidas na sua manipulação, a sua importância econômica e sua necessidade social e cultural (BARROS, 2009). No caso do acervo, a atenção também se concentra nas considerações acerca de seus modos de uso, nas possibilidades de empregos (vestimenta, decoração), no valor que teve (e tem) na moda, nas variações de produção e uso nas diferentes camadas sociais. Além disso, os resultados de pesquisa podem apoiar futuros projetos, em nível de design, moda e história, em contextos sociais, acadêmicos e profissionais.

\section{As ressignificações do fazer renda.}

Diante de tantas perspectivas significativas para delinear o papel da "mulher rendeira" e o "fazer rendas" na sociedade brasileira contemporânea, o estudo analisou 


\section{ModaPalavra E-periódico}

dois cenários sociais principais: a elite e a classe trabalhadora. E pôde verificar que a relação da senhora de elite, nos dias de hoje, com as rendas se modificou: ela não mais tece, não coleciona, não há preocupação com a memória, mas as segue usando em seu guarda-roupas, principalmente com rendas fabricadas industrialmente que atualmente atingem alto grau de expressividade e qualidade. Quando usa as artesanais é porque estão inseridas em roupas de coleções de estilistas de alta moda, como Lino Villaventura, Ronaldo Fraga, Walter Rodrigues, Martha Medeiros, Márcia Gánem, dentre outros que trabalham valorizando e atualizando os fazeres artesanais e tradicionais de nossa cultura.

O cenário se transformou, o modus vivendi é outro. Muitas das mulheres da elite que no início do século passado necessitavam apenas "mostrar" suas prendas e habilidades, hoje estão inseridas no mercado de trabalho, gerenciando o próprio negócio e são profissionais de sucesso. As que não têm uma profissão continuam se envolvendo com atividades sociais, possuem perfil ativo nas redes sociais virtuais, blogs, publicando o retrato de suas vidas e de sua família. Tudo indica que o perfil de mulher como o da Sra. Lucy Niemeyer que tece, usa e coleciona rendas, não existe mais.

Já as mulheres rendeiras da camada mais baixa da sociedade se profissionalizaram e continuam vinculando seu fazer à complementação financeira. Elas se agrupam em cooperativas e associações de artesãs, próximas ou em contato com centros urbanos litorâneos, visando fortalecer sua produção. Dessa forma, impulsionam a produção e comercialização de rendas graças ao fluxo de turistas, grande mercado comprador do produto "rendas", com ênfase em peças de decoração de casa e, em menor quantidade, roupas femininas e infantis.

Nesse contexto, Bergamin (2013) observa as rendeiras de Florianópolis. Segundo a autora, as rendas produzidas visando a comercialização para os turistas, passaram por um processo de transformação, principalmente de meados do século passado em diante. Para aumentar a produção, as rendas de bilros recebem pontos mais simples em sua construção. O mesmo ocorre com a renda filé, produzida no nordeste brasileiro.

Essa estratégia de simplificação dos pontos é também uma forma de facilitar o ensino das técnicas para as novas aprendizes. Segundo Bergamin (2013), até mesmo o material foi alterado e adaptado: fios finos são substituídos por fios mais grossos, os desenhos são mais simples, muito repetidos, diminuindo o tempo para a confecção de determinada renda. 


\section{ModaPalavra E-periódico}

Por outro lado, algumas associações de mulheres rendeiras também desenvolvem projetos orientados por estilistas de moda renomados. Esse tipo de parceria contribui para a manutenção de saberes e dos valores culturais, estimulando o resgate de técnicas e atualização dos desenhos, indicando para uma saída bem mais promissora que a situação apontada anteriormente, da renda feita para turistas. Neste caso, quanto mais elaborado for o ponto mais valor comercial a peça pode atingir, pois trabalha-se com o exclusivo ou com produções de baixa escala. Mas a parceria com estilistas nem sempre supre a necessidade de subsistência das famílias, muitas vezes são projetos pontuais para determinada coleção. Por outro lado, existem os designers de moda que assumem trabalhar somente com rendas, é o caso de Martha Medeiros, Fátima Rendas e Márcia Gánem.

Em ambos os casos o estilista se integra de alguma forma ao grupo de artesãs com objetivos específicos de criação de novos produtos, mas ambos têm uma preocupação econômica e social. Também é comum a existência de projetos que envolvem instituições públicas e privadas como Secretarias de Cultura e Sebrae, integrando e promovendo a participação de designers para melhoria do artesanato. Nesse contexto, um nome importante é o do designer Renato Imbroisi. Junto às comunidades de artesãs, o designer tem desenvolvido um grande trabalho de resgate de técnicas, incentivo a organização de associações. Nessa modalidade de trabalho, oferecem ao mercado peças de design têxtil com valor agregado, contribuindo para a melhoria de aspectos sociais e econômico das comunidades em que atua.

O aprendizado do fazer rendas se dá em grande parte por meio de um processo empírico transmitido de mãe para filha e na interação de círculos sociais, bem como em cursos promovidos por centros de artesanatos. Nesse processo, "o sujeito apropria-se não somente de um fazer, mas de toda a história e valores que o caracterizam e, ao mesmo tempo, imprime a estes sua marca singular" (BALBINOT; PEREIRA; ZANELLA, 2000). Ou seja, cada "mão" que tece, imprime sua maneira de fazer, característica do fazer artesanal.

Importante ressaltar que o interesse pelo aprendizado artesanal, principalmente pelas jovens, vem diminuindo, o que se justifica pela exigência de muitas horas de trabalho e a baixa remuneração (BERGAMIM, 2013). A urbanização crescente das cidades, principalmente nas capitais apontadas neste estudo, possibilita uma maior oferta de trabalhos em outras áreas com maiores salários, afastando as jovens do trabalho artesanal de produção das rendas. 


\section{ModaPalavra E-periódico}

As rendas tecidas e colecionadas no decorrer da vida de muitas mulheres rendeiras, durante séculos, não se perderam, estão hoje em poder dos museus ou instituições culturais e de ensino, cuja missão é salvaguardar o conhecimento, garantindo a memória do "fazer rendas". Dentre os principais museus que possuem acervo dedicado à rendas estão Victoria and Albert Museum (Inglaterra), Powerhouse Museum (Austrália) e Metropolitan Museum of Art (EUA). Quanto às instituições de ensino, a principal é Nothingham Trent University (Inglaterra). No âmbito cultural, destaca-se o Atelier National Du Point d'Alençon (França). No Brasil, o destaque fica por conta do acervo de Luiza e Arthur Ramos, com 1.706 itens de rendas, que hoje pertence ao Departamento de Sociologia do Centro de Humanidades da Universidade Federal do Ceará e pode ser visitado na Casa José de Alencar, em Fortaleza.

Muitas dessas instituições têm acervos com milhares de itens coletados e/ou doados no decorrer dos séculos. Nottingham, universidade inglesa de 1840, possui em seu acervo mais de 75.000 itens de rendas. Essas instituições citadas caminham no sentido de valorizar bens da cultura material, percebendo-os como portadores de saberes. Além disso, preocupam-se em promover a interação de seu acervo com profissionais, estudantes, designers, artistas e pesquisadores.

Nesse mesmo caminho está o acervo de rendas deixado pela Sra. Lucy Niemeyer, que, doado ao Núcleo de Design de Superfície da Universidade Federal do Rio Grande do Sul, está sendo estudado cientificamente para disponibilização virtual, visando atender a uma importante e crescente necessidade: ampliar o acesso às informações e conhecimentos contidas nas rendas para designers, estudantes, pesquisadores e artesãos do país e do exterior.

A metodologia de micro-história empregada neste trabalho permitiu a reflexão do papel da mulher rendeira da elite, apoiado nas informações e suposições da vida da Sra. Lucy Niemeyer, mas principalmente no acervo deixado, contribuindo para organizar o cenário e compreender a realidade e a relação de seus atores.

\section{Referências}

ANDRADE, Rita. Por debaixo dos Panos: cultura e materialidade de nossas roupas e tecidos. In: Tecidos e sua conservação no Brasil: museus e coleções. São Paulo: Museu Paulista da USP, 2006.

BALBINOT, G.; PEREIRA, R.; ZANELLA, A. A renda que enreda: analisando processos de constituir-se rendeira. Educação\&Sociedade, Vol. 21, n. 71. Campinas, 


\section{ModaPalavra E-periódico}

jul., 2000. Disponível em

http://www.scielo.br/scielo.php?script=sci_arttext\&pid=S0101-73302000000200011.

Acesso em 18 fev. 2015.

BARROS, J. de A. Sobre a feitura da micro-história. OPSIS, vol. 7, no 9, jul-dez 2007.

Disponível em www.revistas.ufg.br/index.php/Opsis/article/download/9336/6428. Acesso em 20 abr. 2015.

; História da Cultura Material: notas sobre um campo histórico em suas relações intradisciplinares e interdisciplinares. In: Patrimoniuss, março/2009. Disponível em http://campodahistoria.blogspot.com.br/2011/01/historia-da-cultura-material.html. Acesso em 28 mai.2015.

BERGAMIN, C. A importância da renda de bilro na economia familiar em Florianópolis a partir de 1900 e a sua continuidade no tempo presente. Revista Santa Catarina em História - Florianópolis, v.7, n.1, 2013 . Disponível em www.nexos.ufsc.br/index.php/sceh/article/download/561/270. Acesso em 20 abr. 2015.

BIASOLI-ALVES, Z. M. Continuidades e rupturas no papel da mulher brasileira no século XX. Psicologia: Teoria e Pesquisa. Set-Dez 2000, Vol. 16 n.3, PP. 233-239. Disponível em: http://www.scielo.br/pdf/ptp/v16n3/4810.pdf. Acesso em16 abr. 2015.

BORGES, A., 2011. Design+Artesanato: o caminho brasileiro. São Paulo: Editora Terceiro Nome.

FALCI, Miridan Knox. Mulheres do sertão nordestino. In: DEL PRIORE, Mary (org.) História das Mulheres no Brasil. São Paulo: Contexto, 2010, p. 241 - 277.

GINZBURG, C. Sinais: raízes de um paradigma indiciário. In: Mitos, emblemas, sinais. São Paulo: Companhia das Letras, 1994. p.143-179.

OLIVEIRA, Márcia P. Coleção Luiza Ramos: um nordeste imaginado em rendas. Dissertação de Mestrado - Mestrado em Museologia e Patrimônio. Universidade Federal do Rio de Janeiro. Rio de Janeiro, 2014.

PROWN, J. Mind in matter: an introduction to material culture theory and method. In: PEARCE, S. Interpreting objects and collections. Londres: Routledge, 1994. p. 133138. Disponível em http://blogs.ubc.ca/qualresearch/files/2010/09/Mind-in-Matter.pdf. Acesso em 25 abr. 2015.

RAGO, Margareth. Trabalho feminino e sexualidade. In: DEL PRIORE, Mary. História das Mulheres no Brasil. São Paulo: Contexto, 2010, p. 578 - 606.

SOUZA, G. de M. O espírito das roupas: a moda no século dezenove. São Paulo, Companhia das Letras, 1987. 